\section{Honours and awards}

Jarabak Award

Professor Kevin O'Brien, Professor

of Orthodontics at the School of

Dentistry, University of Manchester,

has been awarded the Louise

Ada Jarabak Memorial award

by the American Association of

Orthodontists Foundation. The

award was presented at a ceremony

at the recent $\mathrm{AAO}$ congress in

Florida, USA. The award has been

made annually since 1983 and

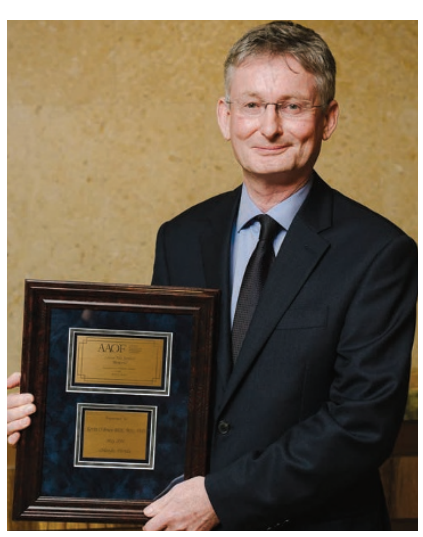

Kevin O'Brien is only the second

UK based orthodontist to receive this recognition of his contribution to orthodontic research and teaching.

Professor O'Brien's main research interests are clinical trials of the care of children with severe dentofacial problems.

www.kevinobrienorthoblog.com
Does dried fruit really damage the teeth?

An independent review published in the International Journal of Food Sciences and Nutrition casts doubt on the perception that eating dried fruit is detrimental to dental health. ${ }^{1}$

Dr Michèle Sadler, an independent consultant in nutrition science, conducted a comprehensive review of the literature and found that the view that dried fruits are 'sticky' and adhere to teeth is based on weak evidence. Dr Sadler says that further research into the effects of chewing dried fruit on the teeth is required, including balancing any detrimental effects against potentially positive attributes such as encouraging salivary flow and the presence of anti-microbial compounds and sorbitol in the fruit. The author also advises taking into account the nutritional benefits of dried fruit when delivering advice on dried fruit consumption.

1. Sadler M J. Dried fruit and dental health. Int J Food Sci Nutr 2016; 1-16 [Epub ahead of print].

\title{
Outcry over Childhood Obesity Strategy
}

There has been widespread criticism of the Government's long-awaited Childhood Obesity Strategy, which ignores recommendations to curb price promotions and tighten advertising restrictions for high sugar products. Running to 13 pages, the document only references childhood tooth decay once.

The British Dental Association (BDA) slammed Ministers' 'relaxed attitude' to health inequalities and combating sugar and referred to the obesity strategy as 'watered down'. The BDA has led calls for joined-up action on sugar and advocates a package of measures including around taxation, effective public education and changes to advertising and marketing.

Chair of the BDA Mick Armstrong said: 'It will take more than half-measures to deal with the sugar crisis. A sugar levy is one thing, but watering down action on junk food advertising and 2-for-1 deals sends entirely the wrong signal to business, parents and health professionals.

'We require a real strategy from government, one that is willing to address the huge, costly and preventable health inequalities Britain now faces. This isn't rocket science, but we need Ministers to take a lead.'

The Oral Health Foundation described the obesity strategy as an 'absolute disaster which will lead to another lost generation of children experiencing entirely unnecessary oral health problems'. Dr Nigel Carter, CEO, said: 'Despite the strategy being focussed on tackling obesity, the knock on effect it would have had on oral

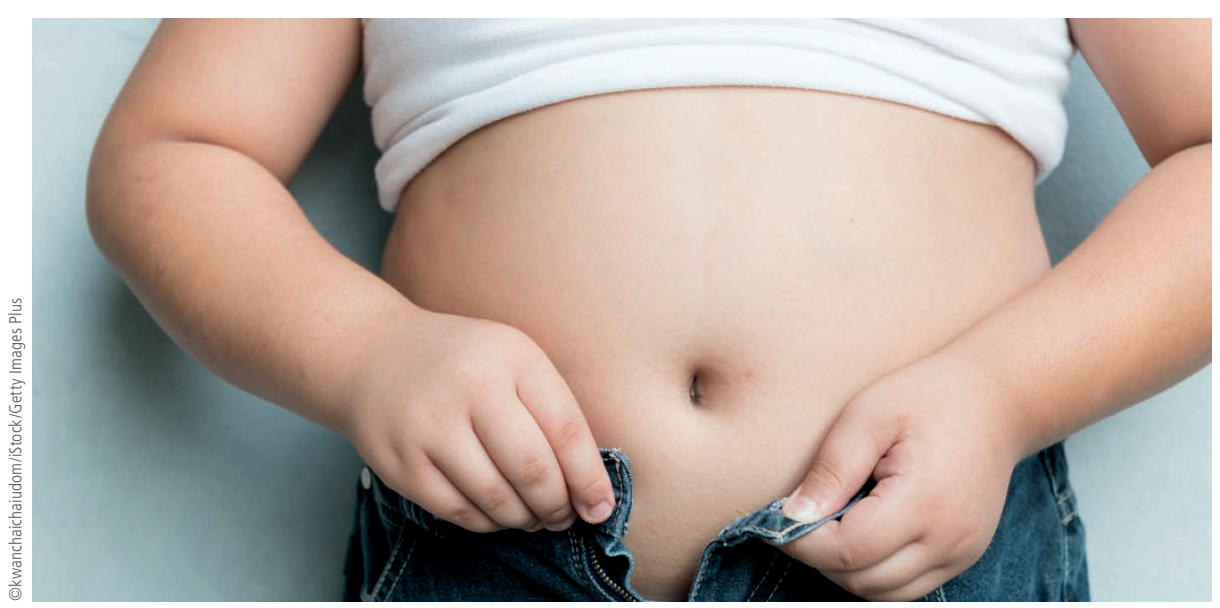

health was enormous and what we have seen spells bad news for generations of our children'

Professor Nigel Hunt, Dean of the Faculty of Dental Surgery, said: 'We have continually drawn attention to the impact sugar has on children's oral health. While we welcome the proposed sugar tax as a big step forward, although the revenue it raises could be used to fund more oral health programmes, the lack of ambition outlined in this Government document leaves a sour taste in the mouth of dentists who have fought hard for tougher measures. The average 5-year-old child eats their own weight in sugar each year so it is crystal clear that much more needs to be done. We will continue to push new ministers hard on further action to protect the nation's oral health.'

The British Society of Paediatric Dentistry (BSPD) said that the published obesity strategy is a missed opportunity. Claire Stevens, BSPD Spokesperson, said: 'Any Government policy which addresses sugar consumption has the potential to impact on oral health. We are very disappointed that this strategy does not go further to reduce sugar content in food. There is no hope that it will make a substantial difference to the number of children requiring general anaesthetics for multiple extractions.

'Earlier this year BSPD called for strong and decisive leadership to address inequalities in oral health once and for all. We are still waiting. 